DOSSIÊ

\title{
POR UMA SOCIOLOGIA HISTÓRICA DA CIRCULAÇÃO E DA RECEPÇÃO DE TEXTOS: \\ ROBERT MICHELS E SOCIOLOGIA DOS PARTIDOS POLÍTICOS NOS ESTADOS UNIDOS ${ }^{1}$
}

\author{
Mario Grynszpan
}

\begin{abstract}
RESUMO
O objetivo deste artigo é, partindo das ponderações de Pierre Bourdieu acerca da importância do estudo das condições sociais da circulação internacional de ideias, fazer uma sociologia histórica da circulação e da recepção do livro Sociologia dos partidos políticos, de Robert Michels. Toma-se como foco a passagem de Michels e de seu livro pelos Estados Unidos, procurando mostrar como consolidou-se a partir dai uma forma de leitura do texto e uma representação do autor que é hoje predominante e que está na base da sua celebração e da sua consagração como um clássico da Ciência Politica. Para tanto, faz-se uma comparação sistemática de diferentes edições e traduções do livro, bem como de resenhas que dele foram produzidas, procurando identificar distintas leituras feitas ao longo do tempo, associando-as com elementos da trajetória biográfica do autor, bem como com a história das Ciências Sociais nos Estados Unidos e, em particular, com a história da Ciência Política nesse país. De um autor pessimista em relação à democracia, ou mesmo com um viés antidemocrático, associado ao fascismo, Michels foi sendo visto no pós-Guerra como um pensador realista e suas teses como base para a formulação de uma noção de democracia identificada com o pluralismo liberal.
\end{abstract}

PALAVRAS-CHAVE: Robert Michels; partidos políticos; circulação de idéias; recepção de idéias; Ciência Política; pluralismo.

\section{INTRODUÇÃO}

Em uma conferência a propósito das relações culturais entre França e Alemanha, em 1989, o sociólogo Pierre Bourdieu chamou a atenção para a importância de uma análise fina das diversas operações sociais envolvidas na circulação de ideias, como forma de promover uma efetiva internacionalização da vida intelectual. Segundo ele, diferentes fatores estruturais são potenciais geradores de mal-entendidos nas trocas intelectuais internacionais. Um deles é o fato de que os textos circulam fora dos contextos nos quais foram produzidos, como textos puros,

\footnotetext{
${ }^{1}$ Este artigo é uma versão modificada de uma apresentação feita no seminário "O centenário de Sociologia dos partidos politicos, de Robert Michels", realizado em agosto de 2011 pelo Programa de Pós-Graduação em Ciência Política da Universidade Federal de São Carlos, sob a coordenação de Maria do Socorro Braga, a quem agradeço pelo convite e a oportunidade.
}

contendo em si tudo que é necessário à sua plena compreensão, sendo lidos a partir de perspectivas, referenciais, contextos por vezes muito distintos dos originais. Daí decorre que o sentido e a função de uma obra estrangeira são determinados também pelo seu novo campo de recepção. Mas essa produção de sentido e função não se dá apenas como resultado de uma leitura descolada do contexto original da obra a partir de um campo de recepção diferente. Ela resulta igualmente de uma série de operações de seleção nos países de destino, como, entre outras, o que será traduzido, por quem, o que será publicado, como, com que marcas, por que editora, coleção, quem será o prefaciador, os resenhistas, como será o lançamento, a divulgação, a distribuição, o que, por sua vez, envolve um conjunto diversificado de agentes e de interesses (BOURDIEU, 2002).

Essas operações e as distintas estratégias de seus agentes são constitutivas das leituras de uma obra, o que nem sempre é percebido ou levado 
em conta. É certo que muitas dessas operações são também realizadas nos campos originais de produção das obras, pesando igualmente sobre suas leituras, produzindo também seus malentendidos. Nesse caso, porém, a proximidade do autor permite algum grau de controle sobre as marcas que serão atribuídas aos seus textos e sua recepção. Na circulação internacional o controle é limitado, por mais que nos tempos atuais a facilidade de comunicação e a mobilidade dos indivíduos venham aumentando rapidamente. Um importante limitador é a tradução, feita em línguas muitas vezes desconhecidas dos autores, o que torna impossível a estes qualquer averiguação da fidelidade da versão estrangeira ao original. Especialistas locais, reconhecidos como autoridades no tema tratado ou no pensamento do autor, são então envolvidos como revisores técnicos, avalizando a versão, atestando com o seu prestígio a sua confiabilidade. O que em contrapartida, é claro, reforça também o prestígio do revisor.

Algumas obras alcançam visibilidade e circulação mais amplas por meio de suas traduções do que em suas versões originais, ganhando aquelas uma autonomia e importância maior do que estas. Isso se dá não apenas quando um texto é traduzido em uma língua que se afirma como internacional, como por exemplo o inglês, mas também quando o país da tradução exerce alguma hegemonia ou imperialismo intelectual, como se refere Bourdieu (idem, p. 3). Nesse caso, a tradução e a sua recepção podem produzir efeitos sobre as obras e as leituras no próprio país de origem, acrescendo a sua importância, gerando debates, tomadas de posição, impondo redefinições em edições futuras. E não é apenas sobre as obras que as traduções produzem efeitos, mas também sobre os autores. Projetando-se para fora, ganhando reconhecimento para além dos espaços intelectuais nacionais - o que é tomado como demonstração de excelência -, eles aumentam a sua visibilidade interna nesses mesmos espaços. Portanto, a circulação internacional não é uma via de mão única, que parte de um ponto original e segue sempre adiante.

Mas se é fundamental atentar para as condições sociais da circulação internacional de ideias, é não somente para evitar os mal-entendidos, as incompreensões, mas também para, tomando-os como entendimentos e compreensões possíveis em contextos deteminados, produzir uma sociologia fina da recepção, da apropriação, das diferentes leituras e usos dos textos. E mais, uma vez que as leituras e os usos se alteram ao longo do tempo, o que fica especialmente evidente no caso das obras que se afirmam como clássicos, com suas várias traduções e reedições, aumentase a fineza e a efetividade dessa sociologia com a incorporação de uma perspectiva histórica ${ }^{2}$.

O objetivo deste artigo é trazer elementos de demonstração do poder heurístico dessa abordagem, tomando por foco o sociólogo alemão Robert Michels. Ele é autor de um livro considerado clássico pelas Ciências Sociais, a Ciência Política em especial, Zur soziologie des parteiwesens in der modernen demokratie. Unter suchungen über die oligarchischen tendenzen des gruppenlebens (MICHELS, 1911) ${ }^{3}$. Embora tivesse produzido centenas de outros textos, entre livros, ensaios, artigos de natureza diversa, sobre temas tão diferentes como castidade, moral sexual, eugenismo, socialismo, sindicatos, economia, comércio exterior, patriotismo, imperialismo, fascismo, foi com Sociologia dos partidos políticos que Michels se consagrou e obteve reconhecimento internacional ${ }^{4}$. Nos quatro anos que se seguiram ao aparecimento em alemão, o livro foi editado em italiano (1912), francês (1914), japonês (1914) e em inglês (1915), sendo que, neste último caso, por duas editoras: uma estadunidense e outra inglesa. Desde então, teve numerosas reedições nessas e em outras línguas ${ }^{5}$.

\footnotetext{
2 Para uma reflexão interessante nessa linha, tomando as diferentes leituras do Ensaio sobre o dom, de Marcel Mauss, ver Sigaud (2002).

3 Daqui em diante Sociologia dos partidos políticos, título da edição brasileira (Michels, 1982).
}

4 A recepção e o reconhecimento de Sociologia dos partidos políticos e a notoriedade de Michels tornaram possível a circulação maior, inclusive com a tradução em línguas distintas das originais, em particular o inglês, de outros textos do autor. Para um inventário da sua produção intelectual, ver Michels (1937, p. 39-76). Uma discussão importante, que poderia ser feita a partir do caso de Sociologia dos partidos políticos, mas que não será possível desenvolver aqui, é a das condições sociais de produção do reconhecimento de uma obra como um clássico. Alguns insights para uma reflexão como essa podem ser tomados, por exemplo, de estudos sobre a afirmação e o reconhecimento da genialidade, como o que faz Norbert Elias (1994) sobre Mozart.

5 As versões italiana e francesa foram traduzidas do alemão e a inglesa do italiano. A versão inglesa foi uma só, publicada por duas editoras distintas. A publicação que se 
Até hoje, é como o autor de Sociologia dos partidos políticos que Michels é celebrado. Mais, sua maior notoriedade vem da sua associação a uma das teses centrais do livro, qual seja, em linhas bastante gerais, a de que toda organização, mesmo igualitária, democrática, desemboca na dominação de delegados sobre delegantes, mandatários sobre mandantes, eleitos sobre eleitores, conhecida como "lei de ferro da oligarquia” (MICHELS, 1982, p. 238). Essa associação, por sua vez, conduziu a outra, vinculando o autor, juntamente com os italianos Vilfredo Pareto e Gaetano Mosca, às origens da teoria das elites e ao que seria uma perspectiva realista da democracia, destacando os limites da ampla participação política e do governo das massas, a inevitabilidade da formação e da imposição de minorias dirigentes ${ }^{6}$. É desse modo que ele é predominantemente apropriado pelas Ciências Sociais, sendo referência obrigatória em cursos, discussões, textos sobre elites, partidos, democracia, teoria política.

Essa cadeia de associações foi produzida e se afirmou ao longo do tempo, sendo alguns de seus elos posteriores à morte do autor ${ }^{7}$. Da mesma maneira, variaram ao longo do tempo as leituras que dela e de cada um de seus elos foram feitas, os significados que lhes foram atribuídos, as conclusões e consequências que foram extraídas e também, por essa via, as representações que foram produzidas do autor. Os modos pelos quais Michels e Sociologia dos partidos políticos são hoje vistos e celebrados são inseparáveis da constituição histórica dessa cadeia, de seus elos, de suas distintas leituras.

está utilizando neste artigo é a americana (Michels, 1915). A edição italiana a que foi possível ter acesso foi a segunda, de 1924 (Michels, 1924 [1912]). Por desconhecimento da língua e pela impossibilidade de ter acesso ao original, a tradução japonesa não será aqui objeto de tratamento. A referência dessa tradução bem como as de outras e de reedições podem ser encontradas em Worldcat (s/d). Michels faz menção à tradução japonesa no prefácio de outras versões e na segunda edição em alemão, de 1925 (MICHELS, [1925] 2001, p. 13).

6 Para um balanço geral da produção bibliográfica associada à teoria das elites ver Grynszpan (1996).

7 Michels nasceu em Colônia, na Alemanha, em 1876, e morreu em 1936 na Itália, em Roma. Ver sua biografia, entre outros, em Linz (1968; 2006), Cook (1971) e Beetham (1977a; 1977b).
São seus herdeiros, trazem a sua marca e, por conseguinte, não decorrem apenas das características e dos elementos internos ao texto, nem somente das intenções do autor. Para melhor dar conta do texto, da sua relevância, do seu reconhecimento, da sua repercussão, da sua circulação, das suas apropriações, das suas exegeses e, da mesma maneira, das formas como Michels foi percebido, é importante ir além do texto em $\mathrm{si}^{8}$.

Cabe ressaltar que não se tem aqui a pretensão de ser exaustivo. Seria inviável, no espaço restrito de um artigo, dar conta da enorme quantidade e diversidade de conjunturas, contextos nacionais e atores envolvidos na circulação e na recepção das muitas versões de Sociologia dos partidos políticos. O que se tentará, mais específicamente, é, analisando formas de recepção e de apropriação de Michels e de Sociologia dos partidos políticos nos Estados Unidos, mostrar como se consolidou uma cadeia de associações que está na base dos modos pelos quais são ambos, hoje, lidos e celebrados. A passagem pelos Estados Unidos confluiu, sobretudo, para a afirmação da percepção do trabalho de Michels como uma reflexão realista sobre a democracia e não estritamente como expressão de um pensamento antidemocrático.

Na verdade, a passagem pelos Estados Unidos foi definidora de uma forma de apropriação não apenas de Michels, que vivia na Itália quando escreveu e publicou Sociologia dos partidos políticos, mas também dos outros dois pensadores italianos aos quais é associado como formulador da teoria das elites, Mosca e Pareto. Foi a partir dos Estados Unidos que, em larga medida, a teoria das elites se difundiu com maior força, incorporando-se à reflexão nas Ciências Sociais de maneira mais ampla, e na Ciência Política em particular. Isso é reconhecido mesmo por autores italianos, como Luigi Graziano (1991, p. 128), Giorgio Sola (1996, p. 48-49), Ettore Albertoni (1985; 1989a, p. ix-lxii) e também Norberto Bobbio

\footnotetext{
8 David Beetham (1977a) chama a atenção para o fato de que a associação exclusiva entre Michels e Sociologia dos partidos politicos, produzindo uma indiferença em relação aos seus demais textos, gera limitações e equívocos na interpretação deste livro. Para ele, portanto, Sociologia só pode ser compreendido de forma mais densa quando lido conjuntamente com os outros textos do autor.
} 
(1976, p. 365), que chega a afirmar que foi naquele país que o elitismo conquistou o seu direito de cidadania na Ciência Política contemporânea9

\section{TRAJETÓRIA, REDES, EDIÇÕES E TRA- DUÇÕES}

Uma variável a ser levada em conta na leitura de Sociologia dos partidos políticos é a de que edição se tem em mãos. O livro teve duas edições em alemão anteriores à morte do autor: a de 1911 e uma de 1925. Michels inicia o prefácio à segunda edição fazendo referência à boa acolhida e ao reconhecimento de Sociologia, evidenciados por suas diferentes traduções e pelas várias recensões (MICHELS, 2001 [1925], p. 13-14). Esclarece ainda que, motivado pelas críticas e comentários nestas contidos, bem como pelos impactos e mudanças de conjuntura relacionados a eventos significativos ocorridos desde 1911, como a I Guerra Mundial, a Revolução Russa e a ascensão do fascismo, fez alterações no livro segundo ele mesmo de fundo, ainda que sem modificar suas conclusões e argumentos centrais. Estes, em sua opinião, longe de serem negados pelos desenvolvimentos históricos recentes, viam-se reforçados ao mesmo tempo em que suas previsões ganhavam realidade (idem, 19-22).

Mas não foi apenas a história europeia que experimentou mudanças entre as duas edições. $\mathrm{O}$ autor também. As edições correspondem a dois contextos distintos da trajetória de Michels. Em 1911 ele era professor na Universidade de Turim e, por ter abandonado a militância de esquerda havia apenas poucos anos, em 1907, era ainda visto como próximo a esse campo. Já em 1925, embora ocupando uma cátedra na Suíça, na Universidade da Basiléia, mantinha seus laços com a Itália e se acercava do fascismo.

\footnotetext{
9 Isso ganha uma evidência maior no caso de Mosca, cujo reconhecimento inicial circunscrevia-se basicamente aos limites de seu país, ganhando maior projeção internacional apenas com a publicação, nos anos 1930, de The Ruling Class (s/d), tradução de seu livro Elementi di scienza política (1923). É em grande parte pelo título da edição em inglês que Mosca é, até hoje, lido e citado fora da Itália. E mesmo edições mais recentes dos Elementi passaram a ter a tradução americana como referência, como foi o caso da de 1966 organizada por Norberto Bobbio (1966, p. XL), que foi intitulada La classe politica. A esse respeito, ver Grynszpan (1999).
}

Boa parte da reflexão de Michels em Sociologia dos partidos políticos e da empiria que a embasa vem da sua militância no Partido SocialDemocrata da Alemanha (Sozialdemokratische Partei Deutschlands (SPD)), mais especificamente na sua seção de Marburg ${ }^{10}$, e também no Partido Socialista Italiano (PSI) e de suas relações com as esquerdas de outros países, como a França. Suas críticas ao SPD, à organização partidária, à luta parlamentar, o aproximaram do sindicalismo revolucionário francês, embora nunca tivesse a ele formalmente aderido. Publicou artigos em Le Mouvement Socialiste e acercouse de Georges Sorel e desenvolveu uma relação de amizade com Hubert Lagardelle que durou até a sua morte ${ }^{11}$. Essa experiência marcou de modo profundo seu pensamento e muitas das teses contidas em Sociologia dos partidos políticos, inclusive a do seu caráter oligárquico, tiveram sua primeira formulação em textos anteriores de análise e crítica das organizações de esquerda (BEETHAM, 1977a, p. 5-9). Ao mesmo tempo, a militância de esquerda produziu impactos significativos em sua trajetória, com efeitos diversos. Na Alemanha ela resultou no bloqueio de sua carreira acadêmica, determinando a recusa de sua tese de habilitação à docência por parte da Universidade de Marburg. Na Itália, porém, suas relações com simpatizantes e militantes de esquerda lhe garantiram a incorporação como livre docente na Universidade de Turim, vinculado à cátedra de economia política ocupada pelo socialista Achille Loria.

Michels passou a buscar uma posição na Itália, onde já havia vivido para realizar estudos, em Turim mesmo, entre 1900 e 1901, após ter a sua habilitação recusada na Alemanha ${ }^{12}$. Para isso, acionou sua rede de relações, solicitando a ajuda de Achille Loria que, além de realizar gestões junto

\footnotetext{
10 Sobre a seção de Marburg do SPD e sua influência nos textos de Michels, ver Bonnell (2011).

11 Sobre as relações de Michels com o sindicalismo revolucionário francês e com Lagardelle, ver Gianinazzi e Lagardelle (1999). Ver também Pouthier (1986).

12 Michels estudou História e Economia na Sorbonne em Paris, e nas universidades de Munique, Leipzig e HalleWittenberg em Halle an der Saale, onde também fez seu doutorado em História, sob a orientação de Gustav Droysen (MÜLLER, 2002). Ele chegou a ocupar postos temporários de professor em Bruxelas e em Paris, antes de estabelecer-se em definitivo na Itália.
} 
à direção da Universidade de Turim, buscou neutralizar as resistências iniciais do economista liberal Luigi Einaudi, que não considerava que os trabalhos de Michels se enquadrassem no campo da economia ${ }^{13}$. Foi também importante para assegurar o ingresso de Michels na Universidade de Turim uma carta de recomendação que pediu a Max Weber (POUTHIER, 1986, p. 51; MALLANDRINO, 2005). Os contatos entre os dois remontavam a 1906, quando Michels publicou seu primeiro artigo em Archiv für Sozialwissenschaft, analisando o socialismo alemão (BEETHAM, 1977a, p. 12). Desde então sua correspondência tornou-se frequente e Weber acompanhou de perto e comentou a produção intelectual de Michels, inclusive Sociologia dos partidos políticos. Ele chegou mesmo a posicionar-se publicamente de maneira contrária à recusa às pretensões acadêmicas de Michels, tomando-a como exemplo da falta de liberdade de ensino na Alemanha, em um artigo que publicou em Frankfurter Zeitung em 1908 (POUTHIER, 1986, p. 51; RINGER, 2000, p. 142). O contato entre os dois durou até meados da década de 1910, quando divergências políticas sobre, entre outros temas, a participação da Alemanha na I Guerra, levaram-nos a um afastamento ${ }^{14}$.

Michels instalou-se em Turim em 1907 e permaneceu até 1914, quando foi convidado a ocupar uma cátedra na Universidade da Basiléia, onde ficou até $1928^{15}$. Em Turim ele se aproximou de Mosca, que ensinava na mesma universidade, e dos escritos de Pareto, Les Systèmes socialistes (1965 [1902]) em

\footnotetext{
13 As relações com Luigi Einaudi estreitaram-se depois, a ponto de Manon, filha do meio de Michels, casar-se com o filho daquele, Mario. A edição italiana de Sociologia dos partidos politicos é dedicada a Luigi Einaudi, além de Gaetano Mosca, ao político de origem aristocrática Annibale Marazio e ao político e médico socialista Giulio Casalini.

14 A primeira edição de Sociologia dos partidos políticos é dedicada a Weber, referido como querido amigo (MICHELS, 1911). Sobre as relações entre os dois ver Scaff (1981). Para uma análise sistemática do pensamento dos dois autores sobre a democracia moderna, ver Tuccari (1993).

15 A mudança para a Itália foi também o momento da sua ruptura com o SPD. Mais adiante Michels veio mesmo a abrir mão da cidadania alemã, trocada pela italiana a partir de 1913.
}

particular $^{16}$. Para alguns autores, foi a partir do contato e da incorporação sistemática das idéias de Mosca e de Pareto que Michels passou a ver nos problemas que identificava na organização e nas práticas do SPD a manifestação de leis universais incontornáveis, base de Sociologia dos partidos políticos (BEETHAM, 1977a, p. 12).

Portanto, as duas edições de Sociologia dos partidos políticos em alemão com Michels ainda vivo foram controladas por ele e apresentavam variações que refletiam não somente as críticas e as distintas conjunturas mais gerais em que foram publicadas, mas também os diferentes engajamentos e momentos da vida do autor. Contudo, não é apenas para as diferenças entre as edições que se deve atentar, mas igualmente para as que existem entre as suas traduções, sendo que algumas, como a inglesa, eram traduções de traduções.

Michels também procurava exercer algum controle sobre as traduções, revisando o texto quando possível ${ }^{17}$ e negociando com os editores os títulos e quem seriam os tradutores, escolha que expressava suas vinculações políticas e o tipo de leitura do livro que buscava impor. A edição italiana foi a primeira, surgindo já no ano seguinte ao da publicação do original em alemão. Ela saiu por uma editora de Turim, cidade onde Michels se encontrava, e a tradução do alemão foi feita por Alfredo Polledro, que teve uma trajetória política semelhante à sua: militou no socialismo, aproximou-se do sindicalismo revolucionário e vinculou-se depois ao fascismo. Michels (1924 [1912], p. XVI-XVII) acentua no prefácio que a preparação do volume foi um trabalho longo de colaboração entre ele e Polledro, que resultou na reformulação de partes do texto, o que se fez também a partir das críticas à primeira edição alemã, e na sua ampliação, com o acréscimo de

16 Ele se aproximou pessoalmente de Pareto, visitandoo seguidas vezes em sua residência em Lausanne, na Suíça, especialmente a partir dos anos 1910, quando também passou a morar nesse país. As visitas são relatadas por sua filha, Manon Michels Einaudi (1935).

17 Na segunda edição em alemão, Michels (2001 [1925], p. 13) refere-se às edições italiana, francesa, inglesa, americana e japonesa como as que conhecia diretamente $\mathrm{e}$ que haviam sido autorizadas por ele. Esclarece que a edição japonesa ficou sob a responsabilidade de um ex-governador de Formosa, Kozo Mori, e contou com a introdução de um nobre com atuação ministerial, barão Goto. 
um capítulo sobre carcaterísticas acessórias das massas na parte I, B, concernente às causas psicológicas da liderança. Quanto ao título, seguiu a grosso modo o original alemão, que imprimia um caráter amplo à reflexão, abrangendo os agregados políticos de maneira geral: $L a$ sociologia del partito politico nella democrazia moderna: studi sulle tendenze oligarchiche degli aggregati politici ${ }^{18}$. Já na segunda edição italiana, em 1924, Michels optou por um título que sugeria um foco mais circuncrito ao livro: Il partito politico nella democrazia moderna.

O responsável pela segunda tradução, a francesa, de 1914, S. Jankélévitch, foi escolhido por Gustave Le Bon, diretor da coleção na qual o livro foi publicado, a Bibliothèque de Philosophie Scientifique, da editora Ernest Flammarion ${ }^{19}$. A coleção foi criada em 1902, da confluência de duas estratégias: a de Flammarion buscando mudar o perfil e a abrangência de sua editora, até então mais identificada com a publicação de obras literárias de apelo popular, e a de Le Bon no sentido de ampliar sua entrada nos meios intelectuais e universitários, o que não havia conseguido de forma plena mesmo com o sucesso de seu livro Psychologie des foules, de 1895 (LE BON, 1922 [1895]). A coleção visava difundir saberes científicos para para um público não familiarizado, a preços mais baixos e com tiragem maior. De início, foram sobretudo autores da rede de Le Bon, além do próprio, que publicaram na Bibliothèque. Com o sucesso da coleção, porém, outros autores passaram a se interessar. A partir dos anos 1910, e da I Guerra em particular, o padrão inicial da Bibliothèque começou a se alterar, assim como o conteúdo, que passou a contemplar também textos de atualidade, até como forma de ampliar as vendas. Foi nesse contexto que se deu a publicação de Michels $^{20}$.

18 O título alemão, que foi mantido na edição de 1925 , era basicamente o mesmo, sendo que, ao final, referia-se às tendências oligárquicas não dos agregados políticos, mas da vida em grupo. Cf. Michels (1911).

19 Há uma extensa lista de textos traduzidos do alemão ao francês por Jankélévitch, em especial de filosofia e psicanálise, não exclusivamente na coleção de Le Bon.

20 A difusão de textos impressos na forma de coleções se iniciou na França na década de 1830. Psychologie des foules foi publicado em uma coleção anterior de outro editor, Alcan. Sobre a coleção de Flammarion e as estratégias de Le Bon, ver Marpeau (1991; 2010).
A edição alemã de Sociologia dos partidos políticos já tinha tido algumas resenhas na França e sua publicação nesse país resultou da iniciativa do próprio Michels, que abordou Le Bon a respeito. Os contatos e negociações entre os dois se iniciaram ainda em 1911. Para convencer Le Bon, Michels afirmou em uma de suas cartas que o que fazia no livro era aplicar aos partidos políticos as teses desenvolvidas em Psychologie des foules (MOSCOVICI, 1985, p. 85, n. 61). Das exigências do diretor e do perfil da coleção resultaram alterações no livro (GIANINAZZI \& LAGARDELLE, 1999, p. 104, n. 1) - incluindo o fato de que, à diferença do que ocorreu com outras traduções, a francesa não trazia o prefácio à primeira edição alemã. Quanto ao título, que foi também negociado, manteve o foco nos partidos políticos mas, eliminando o adjetivo "moderna", identificou a oligarquia como uma tendência da democracia em geral: Les partis politiques: essai sur les tendances oligarchiques des démocraties.

\section{LEITURAS INICIAIS NOS ESTADOS UNIDOS: MICHELS PENSADOR PESSI- MISTA}

Uma das edições mais citadas de Sociologia dos partidos políticos é a de língua inglesa, a estadunidense em particular. O livro vinha sendo lido nos Estados Unidos desde que foi publicado em alemão. Uma das primeiras resenhas, do ano mesmo da publicação, foi de Robert C. Brooks (1911), cientista político da Universidade de Cincinnati, em Ohio. Para ele, o livro era uma crítica dura à organização e à liderança do SPD, feita por um socialista. Depois de elogiar o trabalho por seus insights, pelo uso que fazia da Psicologia, embora não tanto o da Psicologia das Multidões, o resenhista destaca como um limite seu tom excessivamente pessimista quanto à participação das massas na política. Afirma ele que, se Michels tivesse dado maior atenção à história e à organização dos partidos na Inglaterra e nos Estados Unidos, suas conclusões seriam matizadas. Outra resenha nesse mesmo ano foi a de Albion Woodbury Small (1911), que ocupou a primeira cadeira de Sociologia nos Estados Unidos, a da Universidade de Chicago. Para ele, o livro era leitura obrigatória para todo estudioso de Psicologia Social. Aqui já não é o socialismo que é destacado como o problema central de Michels, mas a democracia e, nela, os partidos políticos. Small destaca que, em parte, questões levantadas por Michels já se encontravam em 
Ostrogorski. No entanto, o livro de fato abria novas vias de análise, sobretudo no que dizia respeito à questão da liderança. Não se podia ignorar, porém, seu argumento de que a democracia era essencialmente patológica. Nesse ponto, Small levanta a possibilidade de que Michels fosse um adepto da monarquia eclesiástica, uma vez que cita Karl Ludwig von Haller, defensor da restauração ${ }^{21}$.

Ou seja, não havia ainda uma percepção de Michels como um analista realista da democracia. Era como um crítico pessimista, ou mesmo antidemocrático, que era visto. Sua tese central, embora reconhecida como pregnante, tinha a sua validade restrita à Alemanha, ou mesmo ao SPD. Além disso, o autor ainda era relativamente desconhecido, como fica claro no texto de Small. Por outro lado, o fato de alguém na posição de Small dedicar seu tempo à redação de uma resenha do livro é também um indicador da sua repercussão. Michels (1924 [1912], p. XXI) observa, no prefácio à primeira edição italiana, em 1912, que Sociologia dos partidos políticos vinha sendo tema de discussão de estudantes de Ciências Sociais de Chicago. De fato, Chicago teve um papel importante na difusão do livro nos Estados Unidos.

A edição americana de 1915 resultou da tradução da italiana de 1912, feita pelo casal inglês Eden e Cedar Paul. Maurice Eden Paul era um médico, filho do editor Charles Kegan Paul, e Cedar Paul, originalmente Gertrude Mary Davenport, uma cantora oriunda de uma família de músicos de renome. Ambos eram militantes de esquerda, com passagem pelos partidos Trabalhista Independente e Comunista da GrãBretanha. O subtítulo de Political parties reintroduziu a ideia de que se tratava de um estudo sociológico sobre as tendências oligárquicas da democracia moderna. Esta edição também não

21 Michels tomou conhecimento das duas resenhas rapidamente $\mathrm{e}$ fez referência a elas já no prefácio à primeira edição italiana, em 1912. Quanto a Brooks, a quem chama de amigo, diz que suas críticas eram um tanto injustas, sobretudo no mau uso da psicologia das multidões, mas que não dedicaria tempo a respondê-las. No caso de Small, a reação foi mais dura e dizia que citar alguém em um trabalho científico objetivo, como o dele, não significava uma adesão às ideias políticas do citado (MICHELS, 1924 [1912], p. XXI-XXII). contém o prefácio alemão, nem o italiano, mas o texto de abertura que Michels escreveu para a edição em inglês é bem semelhante a ele. O autor observa que a versão em inglês trazia alterações em relação às anteriores, resultado da incorporação das críticas que foram feitas. Também foi introduzida uma reflexão sobre a I Guerra, iniciada no ano precedente, o que resultou em um capítulo novo sobre a vida partidária em tempo de guerra (MICHELS, 1915, p. IX).

Recensões surgiram no período imediatamente após a publicação. Nelas, a novidade do trabalho de Michels estava não na sua tese central de que a democracia produzia minorias e de que estas buscavam se consolidar no poder como oligarquias. Para alguns, como o historiador da Universidade de Columbia Charles Austin Beard, a tese de Michels era quase um truísmo para quem conhecia Aristóteles, Ostrogorski ou o líder de sua localidade. O autor, segundo ele, apenas acrescentava um capítulo novo a uma história antiga. E o que Michels trazia de novo, na avaliação geral, era a empiria, a grande quantidade de dados e detalhes que organizou e trabalhou sistematicamente para demonstrar sua tese. E isso, também na avaliação geral, era o que conferia importância ao trabalho. Contudo, diziam os resenhistas, os dados trazidos por Michels eram específicos da sua experiência com partidos de socialistas da Europa continental, o alemão em particular, o que, para Edwin D. Dickinson, cientista político do Dartmouth College, tornava enganadores o título e o prefácio do livro. Segundo ele, Sociologia não era um estudo da natureza dos partidos políticos e sim uma análise da organização e do controle especificamente de partidos de esquerda, e da Europa continental. O principal problema do livro, até como decorrência do foco exclusivo do seu material empírico e da experiência concreta do autor, como parecia ser consenso nas recensões, era o fato de que expressava uma visão pessimista em relação à democracia, podendo servir à causa dos que buscavam negá-la. Segundo Clyde Lyndon King, cientista político da Universidade da Pensilvânia, o tom hipercrítico do argumento beirava a virulência, o que era seu maior defeito (DICKINSON, 1916; KING, 1916; BEARD, 1917; BURNS, 1917).

A leitura de Michels como um pensador pessimista ou mesmo antidemocrático ganhou espaço na década de 1920, com a sua associação 
ao fascismo, que se deu na mesma época em que liberais que apoiaram a ascensão de Mussolini, como Gaetano Mosca, começaram a se opor ${ }^{22}$. E foi tendo Michels como um pensador associado ao fascismo que dele se aproximou Charles Edward Merriam, cientista político da Universidade de Chicago e um dos principais nomes no processo de afirmação e profissionalização das Ciências Sociais nos Estados Unidos, a Ciência Política em particular.

IV. CONTEXTO INSTITUCIONAL DE RECEPÇÃO NAS CIÊNCIAS SOCIAIS ESTADUNIDENSES

Os estudos de história das Ciências Sociais nos Estados Unidos apontam para o final da I Guerra Mundial como um momento de mudanças significativas $^{23}$. Ele marca, se não um abandono dos ideais reformistas que caracterizaram o período anterior, pelo menos uma alteração fundamental nas visões acerca da sociedade, das transformações pelas quais passava e, mais do que isso, do lugar e do papel dos cientistas sociais nessas transformações, da sua competência e da sua capacidade de intervenção nos processos sociais e políticos. Até então, não havia, de modo claramente demarcado, uma autonomia entre atividade intelectual e militância social e política. A questão principal que se colocava para os cientistas sociais, diante das migrações, dos deslocamentos, dos conflitos, da acentuada diferenciação social, da desarticulação da vida em pequenas comunidades, entre outras decorrências da crescente urbanização e da industrialização, era a de como combinar progresso e democracia. As

22 Mussolini chegou ao poder em 1922, com o apoio dos liberais. Eles foram tornando-se oposição a partir de 1924, com o assassinato do deputado socialista Giacomo Matteotti por fascistas.

23 Ainda que variem em relação aos seus objetivos, à fineza de sua análise, de suas demonstrações, e ao sentido de suas explicações, há uma forte concordância entre os estudos no que diz respeito aos cortes cronológicos fundamentais da história das Ciências Sociais nos Estados Unidos, às características básicas de cada período, suas preocupações, temáticas principais e atores centrais. A análise aqui desenvolvida tomou por base Easton (1964), Somit e Tanenhaus (1967), Carey (1975), Waldo (1975), Ricci (1984), Karl (1985), Seidelman e Harpham (1985), Bannister (1987), Farr e Seidelman (1993), Ross (1997), Worcester e Sibley (2001) e Calhoun (2004).
Ciências Sociais deveriam estar comprometidas com reformas que reinstaurassem uma situação de igualdade e que promovessem a participação percebidas como valores originais, fundadores da sociedade americana -, sem obstar o desenvolvimento.

O que se observou de fato a partir da I Guerra e durante toda a década de 1920 , no entanto, foi um movimento de autonomização, de distanciamento, de separação entre ciência e atividade política. Embora não tivesse ocorrido uma ruptura com os princípios democráticos, o otimismo do período anterior foi substituído por um marcado ceticismo. A própria guerra, a recente revolução russa, as crescentes críticas ao liberalismo na Europa em geral e, nos Estados Unidos, a derrota eleitoral e o fracasso político de líderes identificados como portadores de um discurso e de propostas progressistas colocaram para os cientistas sociais a necessidade de refletir sobre o fato de que princípios tidos como justos, por si sós, não eram suficientes para produzir um reconhecimento generalizado, uma adesão dos indivíduos que se traduzisse em ações, em atitudes consideradas mais adequadas ou racionais. Na verdade, a idéia mesmo de racionalidade das atitudes humanas passou a ser objeto de questionamento.

Mais do que simplesmente promover reformas, tratava-se agora de conhecer seus obstáculos, saber o que as impedia, de modo a elaborar políticas mais eficazes, cientificamente orientadas. Não cabia aos cientistas sociais fazer as reformas, mas o conhecimento por eles produzido poderia e deveria ser utilizado por aqueles que tinham essa função.

O modelo de Ciência Social que se foi conformando aproximava-se do das Ciências Naturais, o que implicou na incorporação e na generalização da crença cientista de que, da mesma forma que na natureza, os processos sociais eram cognoscíveis e, assim também, previsíveis pelo emprego de um método objetivo, rigoroso, que se baseasse na exaustividade e em medidas precisas. Mais do que a imposição de um método científico legítimo, isso significou que o seu controle, a competência no seu emprego, passou a ser um dos atributos básicos de reconhecimento dos cientistas sociais. A formação dessa competência específica, por sua vez, tornou-se uma atribuição exclusiva dos departamentos universitários. 
Operou-se, portanto, um processo de profissionalização que se traduziu na crescente exigência de títulos universitários e que teve como contrapartida a gradual ilegitimação e exclusão do amadorismo. Isso levou não apenas a uma expansão numérica dos departamentos de Ciências Sociais, mas também a uma redefinição das posições de importância relativa de cada um deles, assistindo-se ao declínio dos identificados com posturas e visões tidas como mais antigas e à ascensão dos que puderam se afirmar como inovadores, colocando-se à frente de todo esse conjunto de mudanças, impondo como gerais os seus próprios padrões de excelência, de relevância, de reconhecimento.

Para que os porta-vozes da nova perspectiva científica consolidassem sua posição foi importante a sua presença à frente de associações profissionais como a American Political Science Association (APSA). Fundamental, contudo, foi o fato de terem sido eles os responsáveis pela criação, em 1923, do Social Science Research Council (SSRC). Intermediando, definindo a alocação dos recursos que começavam a fluir para a pesquisa em Ciências Sociais a partir de entidades filantrópicas como o Laura Spelman Rockefeller Memorial Fund, a Carnegie Corporation, o Julius Rosenwald Fund e a Russell Sage Foudation, o SSRC pôde propiciar a criação ou a expansão de departamentos, possibilitar a projeção de pesquisadores e produzir, objetivamente, uma confluência para o que seria o método científico legítimo ${ }^{24}$. Para além disso, foi a própria agenda de pesquisas, a hierarquia de objetos cientificamente relevantes que se redefiniu, passando a ganhar maior importância aqueles que eram passíveis de mensuração. Atitudes, participação eleitoral, opinião pública, propaganda, liderança, tornaram-se algumas das temáticas privilegiadas, articuladas a uma preocupação central com o problema do controle social, tomando-se a Psicologia, particularmente de base comportamental, como referencial explicativo dominante.

Foi esse o momento em que Merriam se projetou, tornando-se, a partir dos 1920, uma das figuras de maior visibilidade e importância nas Ciências Sociais americanas, ocupando postos de prestígio e de

24 Para uma história especificamente da Fundação Rockefeller, ver Fosdick (1989). poder, impondo padrões e objetos legítimos de trabalho, formando aqueles que passariam a ocupar posições dominantes na Ciência Política. Identificado com a perspectiva reformista progressista que havia caracterizado o período anterior à I Guerra Mundial, ele se envolveu diretamente com a política municipal de Chicago, galgou cargos eletivos e se afirmou como forte possibilidade para a prefeitura da cidade. Derrotado em 1919, porém, operou um redirecionamento de seus investimentos pessoais, o que lhe permitiu não apenas projetar seu departamento na Universidade de Chicago, mas também tornar inseparável de sua trajetória individual a própria história da Ciência Política, e mesmo das Ciências Sociais, nos Estados Unidos ${ }^{25}$.

Das lutas partidárias, Merriam passou a investir pesadamente na militância e nas disputas científicas, tornando-se um dos principais promotores do processo de profissionalização das Ciências Sociais. Foi ele um dos mais notórios porta-vozes de uma perspectiva cientista, defensor de um método objetivo, rigoroso e preciso como o das ciências naturais, o que lhe parecia ser o único meio de romper com uma inferioridade das Ciências Sociais no que dizia respeito tanto à verificabilidade e à validade científica de seus conhecimentos, quanto à sua aplicabilidade e ao seu prestígio social (ALMOND, 1988, p. 838). Sua possibilidade de generalizar e objetivar suas propostas, fazendo com que fossem reconhecidas e incorporadas em práticas científicas efetivas, estava diretamente associada ao fato de ter sido ele o criador e um dos principais nomes do SSRC.

Merriam soube capitalizar sua competência e seus recursos políticos, mobilizando suas redes de relações de modo a canalizar os investimentos de fundos e instituições filantrópicas, viabilizando a estratégia do SSRC. Igualmente importantes foram os seus vínculos pessoais no campo das ciências naturais, tomadas como paradigma não apenas científico, metodológico, mas também de organização profissional. Seu irmão mais velho era o biólogo John C. Merriam, que em 1918 dirigiu o National Research Council, então focado nas ciências naturais e uma das inspirações do SSRC.

Com Merriam à frente do SSRC, o departamento de Ciência Política de Chicago passou a receber recursos consideráveis, ascendendo, ganhando

25 Para um acompanhamento sistemático da trajetória de Merriam, ver Karl (1974). 
prestígio e projeção no espaço universitário, produzindo uma boa parte das investigações e dos trabalhos reconhecidos como mais relevantes, afirmando a percepção de seus pesquisadores como alguns dos mais brilhantes, capazes e influentes, e de seus alunos como bem formados e competentes (DAHL, 1961, p. 763). Afastado da atividade política em sentido estrito, Merriam fez dela um dos objetos centrais de reflexão da Ciência Política, buscando consolidá-la enquanto ciência da política, elaborando sua própria experiência pessoal, da qual advinha parte do elenco daquelas que se impuseram como temáticas relevantes de pesquisa: atitudes políticas, comportamento eleitoral, liderança e popaganda. E foi pensando em propaganda e educação cívica como formas de controle social e como bases importantes do comportamento político que Merriam aproximouse de Michels, esperando deste uma visão de como ambas operavam na experiência fascista.

O interesse de Merriam pela propaganda e pelo caso italiano vinham da I Guerra. Assim como outros intelectuais, ele colaborou com o esforço de guerra americano, trabalhando no U. S. Committee on Public Information, cujo objetivo era formar uma opinião pública nacional unificada favorável à participação, legitimando-a, garantindo bases de apoio eficazes, o que significava, igualmente, exercer a censura e neutralizar vozes discordantes (GRUBER, 1975; ROSS, 1997). Sua ação começou a voltar-se também para a Europa a partir da Revolução Russa e da conseqüente saída do país da guerra, que forneceu combustível às campanhas antibelicistas promovidas por grupos pacifistas e, em especial, por partidos de esquerda, que experimentavam um claro fortalecimento. Foi para fazer face a isso, e aos seus possíveis efeitos negativos sobre o desenrolar do conflito, que o governo americano abriu escritórios do comitê na Europa, um deles em Roma. Merriam esteve à frente do escritório de Roma em 1918, estabelecendo contato com políticos, intelectuais e empresários italianos, difundindo a ideia de que a participação dos Estados Unidos e a vitória eram fundamentais para o futuro da democracia no mundo. Ao retornar, publicou um artigo na American Political Science Review, "American Publicity in Italy", em que afirmava que a grande guerra desenvolvera diversas armas novas, sendo uma das mais letais a propaganda (MERRIAM, 1919, p. 541).

Merriam começou a corresponder-se com Michels em 1926, convidando-o a publicar em uma série de estudos monográficos sobre educação cívica cujo título seria Studies in the Making of Citizens. Autores de diferentes países escreveriam sobre suas respectivas experiências nacionais. Caberia a Michels o volume sobre a Itália. O foco desejado por Merriam, nesse caso, era o do fascismo. Além disso, pretendia que Michels viesse a Chicago para dar um curso sobre partidos políticos e teoria política e social recente. A viagem terminou por se concretizar em 1927, tendo Michels proferido palestra no Instituto de Política em Williamstown, Massachussets, e dado um curso de verão em Chicago sobre partidos políticos em perspectiva comparada, juntamente com Merriam e dois de seus alunos e assistentes que se tornaram mais reconhecidos, Harold Foote Gosnell e Harold Dwight Lasswell. O texto, porém, frustrou Merriam, não tocando na questão do fascismo (KARL, 1974, p. 169-185).

Para os cientistas sociais americanos, portanto, Michels era associado ao fascismo na década de 1920. De fato, pouco tempo após retornar dos Estados Unidos, em 1928, ele deixou a Universidade da Basiléia pela de Perugia, encarregado pelo próprio Mussolini de ministrar cursos de Ciência Política cujo objetivo era formar a elite do sistema fascista, o que fez até 1936, com a sua morte. Seus obituários nos Estados Unidos enfatizaram seu vínculo com o fascismo. Em uma pequena nota de 7 de maio de 1936, o jornal The New York Times comunicou o falecimento e destacou o fato de Michels ser Professor de Perugia por nomeação de Mussolini (ROBERTO MICHELS, ECONOMIST, DEAD, 1936). O texto em memória de Michels publicado na American Sociological Review era de autoria de um sociólgo também vinculado ao fascismo, Dino Camavitto (1936), da Universidade de Roma. E o American Journal of Sociology (OBITUARY, 1936) lembrou que o afastamento de Michels do socialismo alemão levou-o ao encontro dos movimentos sindicalistas e antidemocráticos na França e na Itália, o que resultou, mais tarde, na sua associação ao fascismo. Ressaltou ainda a importância de Sociologia dos partidos políticos, que definiu como sendo essencialmente uma análise do socialismo préguerra na Alemanha, com algumas miradas para a França, Itália, Inglaterra e América, mas que se afirmou também como uma das grandes fontes da argumentação teórica contrária à democracia.

\section{OS CIENTISTAS SOCIAIS AMERICANOS, O FASCISMOEADEMOCRACIA}

Até meados dos anos 1930, a associação de Michels com o fascismo não era exatamente um 
problema para os cientistas sociais americanos. Embora houvesse oposição, não havia ainda, até aquele momento, uma condenação mais ampla a Mussolini e ao fascismo nos Estados Unidos. Entre os cientistas sociais havia mesmo mais do que uma curiosidade, uma certa fascinação por ele e pelo que se poderia aprender com ele. O próprio Merriam se referia ao fascismo italiano como um experimento notável, cuja natureza antidemocrática não deveria ser um obstáculo ao estudo dos seus aspectos $\operatorname{positivos}^{26}$.

É preciso ver que, se de um modo ou de outro foram as possibilidades de promover e aperfeiçoar a democracia que estiveram no centro das preocupações dos cientistas políticos, a partir de fins dos anos 1920 observa-se uma importante mudança. Até a I Guerra Mundial, o que se buscava era a promoção de valores então considerados básicos da democracia, a igualdade, a participação, tidos como fundadores, marca específica da sociedade americana. A partir dali, ainda que não mais prevalecesse o otimismo anterior, o que se procurava descobrir eram os obstáculos à efetivação daqueles valores, de modo a que pudessem ser retirados. Já no final da década de 1920, e durante a seguinte, era a própria noção de democracia que passava a ser objeto de questionamento, tomandose os problemas políticos e sociais então existentes não como decorrentes de uma inobservância ou de uma aplicação incompleta dos valores democráticos, mas, ao contrário, como resultantes mesmo da sua efetivação.

Noções como "igualdade", "participação", "soberania popular", "vontade da maioria" começavam, se não a serem dissociadas da ideia de democracia, a serem vistas de modo distinto, relativizadas. Isso era feito tomando por evidência os próprios regimes totalitários que, ao menos nos casos da Alemanha e da Itália, ascenderam a partir de mecanismos eleitorais, que tinham sem dúvida o apoio de uma parcela expressiva das respectivas populações, podendo, portanto, apresentar-se como expressão da vontade popular, que se legitimavam, entre outras formas, por grandes mobilizações ou manifestações de massa, e que se diziam, o que na vertente do comunismo alcançava o paroxismo, realizações mais autênticas da ideia de igualdade.

26 Sobre as visões dos cientistas políticos americanos em relação ao fascismo, ver Oren (2000).
Questões como essas vinham se tornando centrais nos Estados Unidos não apenas pela sua relevância no quadro externo, pelo crescente clima de tensão nas relações internacionais, mas também porque se referiam a problemas concretos enfrentados no país, mais intensamente a partir da crise de 1929. Um dos desdobramentos da crise, da depressão econômica e de seus extensos e dramáticos efeitos sociais, foi o processo de centralização que resultou na reorganização, no crescimento, no fortalecimento, na afirmação do Executivo como um ator primordial, deslocando-se do Congresso para ele o eixo dinâmico fundamental da política, o que se efetivou com Roosevelt e o New Deal27.

A necessidade dessa mudança vinha sendo acentuada por autores como Walter Lippmann, que falava da incapacidade das democracias liberais representativas para lidar com os problemas presentes, resultado de um desequilíbrio entre os poderes que conferia um peso excessivo às assembléias eleitas e às opiniões das massas. Era preciso romper com isso, liberando o Executivo das pressões de uma opinião pública que, por via de regra, mostrava-se equivocada, de assembléias que, na verdade, representavam interesses particulares de grupos oligárquicos ${ }^{28}$. A discussão que se colocava, por conseguinte, era a de como operar a centralização do Estado e o fortalecimento do Executivo sem romper com a democracia, sem desembocar no totalitarismo.

Essa discussão assumia, em especial para o departamento de Ciência Política de Chicago, um sentido bastante prático, tendo em vista o envolvimento direto de Charles Merriam com o processo de reorganização do poder Executivo. A reaproximação de Merriam com a atividade política, agora na condição de consultor, de especialista, vinha se dando desde fins dos anos 1920 - período que coincidiu com a redução gradual dos recursos para a pesquisa científica advindos das fundações filantrópicas -, quando o presidente Herbert Hoover

27 Para um estudo do processo de reorganização do Executivo e seus efeitos ver Karl (1979).

28 Ainda que escrito nos anos 1930, o texto referido apareceu em Lippmann (1955). Na verdade, já em seus escritos da década de 1920 Lippmann (1922; 1925) argumentava que a opinião pública era essencialmente irracional, o que representava um problema para a democracia. 
criou o Committee on Recent Social Trends. Tratava-se de uma comissão de caráter técnico, coordenada por aquele cientista político, pelo sociólogo William Ogburn, então também em Chicago, e pelo economista Weslley Mitchel, de Columbia, cujo objetivo era traçar um diagnóstico dos recursos e dos problemas sociais do país, bem como indicar suas possíveis tendências.

A iniciativa de Hoover marcava a abertura de novos espaços de intervenção, de possibilidades extra-acadêmicas de afirmação para os cientistas sociais americanos, processo que veio a se intensificar com a vitória de Roosevelt, em 1932, e o New Deal. Foi nesse momento que eles passaram a se impor como técnicos, especialistas, consultores, planejadores, atuando junto aos diversos órgãos e comissões que foram sendo criados pelo Executivo. Colocando suas competências específicas a serviço da formulação e da análise de políticas públicas, eles se projetaram como provedores de orientações políticas, acumulando prestígio, notoriedade, relações e um conhecimento interno da máquina governamental e do processo de tomada de decisões que, em contrapartida, fortalecia também suas posições acadêmicas, garantia o acesso a financiamentos e traduzia-se em publicações. Merriam esteve à frente de tudo isso, passando por funções de planejamento e vindo a afirmar-se como um dos principais conselheiros de Roosevelt (KARL, 1979).

Em um tal quadro, as ideias de Michels, mas também as de Mosca e Pareto, constituíram-se para os cientistas políticos em fundamento de legitimidade, ao mesmo tempo de uma nova configuração política e da posição que nela passaram a ter. Diferentemente do que ocorreu na Itália, em que foram tomadas como base de fundamentação do fascismo, mesmo que não necessariamente por iniciativa dos autores, como foi o caso de Pareto, que morreu no ano seguinte ao da chegada de Mussolini ao poder, ou de Mosca, que se tornou um opositor, essas ideias foram apropriadas não de modo a negar, mas a elaborar uma perspectiva distinta de democracia. Nela a ênfase recaía sobre a noção de liberdade em vez de igualdade, relevava-se a representação em detrimento da participação, deslocava-se do centro de sua definição a idéia de governo do povo, de vontade da maioria, de soberania popular, para substituí-la pela de minorias dirigentes, salientando-se, contudo, a absoluta necessidade de procedimentos que garantissem a abertura dessas minorias e o pluralismo, a ampla concorrência entre elas.

\section{DE PESSIMISTA A REALISTA: RELEI- TURAS DE MICHELS}

A apropriação de Michels, Mosca e Pareto como bases para uma concepção de democracia não se deu sem problemas nem sem operações intelectuais e justificativas complexas, sobretudo a partir de meados da década de 1930, quando o regime de Mussolini foi se ilegitimando nos Estados Unidos. No caso de Mosca, visto como um opositor, o contexto foi positivo, criando condições favoráveis à publicação de The Rulling Class, que já vinha sendo preparada, e postergada, desde os anos 1920 (ALBERTONI, 1989a, p. xviiixix). Contribuiu também para isso o trabalho de críticos de Mussolini que se encontravam refugiados nos Estados Unidos, como o filho de Luigi Einaudi e genro de Michels, Mario, cuja intervenção junto à editora McGraw-Hill foi fundamental para garantir a publicação (LIVINGSTON, s/d, p. xli; ALBERTONI, 1989a, p. xxvi). No caso de Pareto, cultuado por Mussolini, o que buscaram seus intérpretes e comentadores foi dissociá-lo do totalitarismo, negando o epíteto de "Karl Marx do fascismo" que lhe era atribuído ${ }^{29}$. Enfatizou-se a neutralidade política de suas formulações, apresentando-as como estritamente científicas, objetivas, desinteressadas, destacando que a única relação que havia entre Pareto e o fascismo era o fato de que a ascensão deste comprovava as leis científicas descritas por aquele (BONGIORNO, 1930). Em segundo lugar, buscou-se caracterizar o autor como uma personalidade absolutamente independente e, portanto, impossível de ser rotulada, o que fazia dele um crítico e não um adepto ou apologista das ideologias (EINAUDI, 1935).

No caso de Michels, reconhecidamente vinculado a Mussolini e ao fascismo, uma operação semelhante foi realizada. Passaram a ganhar espaço leituras de Sociologia dos partidos politicos como uma análise puramente científica, objetiva, baseada em evidências incontestáveis, cujas teses expressavam, portanto, não uma tomada de posição,

29 O termo, que já vinha sendo usado na Europa, apareceu no artigo de Worthington (1933). 
mas uma constatação da inevitabilidade da oligarquia como um obstáculo incontornável à efetivação da democracia. Mas a democracia inviável, segundo essas leituras, era a ideal, fundada nas ideias de Rousseau ou no igualitarismo radical pregado pelas esquerdas. Era quanto a ela que Michels mostravase reticente, pessimista. Se apontava a sua inviabilidade era não a partir de uma perspectiva antidemocrática, mas realista. $\mathrm{O}$ que permitia que Sociologia fosse visto como uma negação da possibilidade da democracia em geral era o fato de que, nele, Michels olhava apenas para a estrutura interna dos partidos, deparando-se com a "lei de ferro da oligarquia". Um investimento seguinte, que o autor não pôde realizar, o estudo das relações entre os partidos, revelaria a viabilidade de mecanismos de controle da oligarquização, de garantia da liberdade de expressão e de concorrência, do pluralismo, de uma democracia real. Mas se na ciência Michels era um realista, na política, concluíam essas leituras, ele era em grande parte um idealista que se ligou ao socialismo na juventude e que, mais adiante, vinculouse ao fascismo, vendo em Mussolini o líder carismático que poderia conduzir as massas.

Um dos autores importantes na releitura das ideias de Michels, Mosca e Pareto foi o filósofo James Burnham, da Universidade de Nova York. Antigo militante do Socialist Workers Party, de orientação trotskista, Burnham apoiou-se naquelas ideias na sua crítica e ruptura com a esquerda ${ }^{30}$. Em 1943 ele publicou The Machiavellians, qualificando os três pensadores como defensores da liberdade, subtítulo do livro. Longe de serem opositores da democracia, o que Michels, Mosca e Pareto faziam, segundo Burnham (1943), era atacar a crença no mito da democracia enquanto governo da maioria, expressão da soberania, da vontade popular, apresentando uma noção mais concreta, viável, fundada na percepção de que todo governo é sempre de uma elite e que o importante era a existência de mecanismos efetivos de mudança e de controle do poder da elite governante, garantindo a existência de uma oposição livre, pública. Porém, em meio à II Guerra Mundial, alardeada como uma luta entre a liberdade e o totalitarismo, relativizações da democracia não encontravam grande espaço. A repercussão do livro de Burnham, assim, não foi imediata.

Foi também apenas depois da guerra, em 1949, que Sociologia dos partidos políticos teve a sua

\footnotetext{
30 Sobre a trajetória de Burnham, ver Borgogne (1999).
}

primeira reedição nos Estados Unidos, a primeira de muitas. Foi a partir daqui que o livro se difundiu de maneira mais ampla nesse país ${ }^{31}$. Embora resenhas da edição de 1949 ainda ressaltassem o pessimismo do autor e os possíveis desdobramentos totalitários de suas teses, destacava-se igualmente a sua importância para uma reflexão sobre os marcos e as garantias de uma democracia real. Esse era o tom da análise de John W. Lederle (1949), da Universidade de Michigan. Segundo ele, o tema central do livro eram as limitações organizacionais que impediam a realização do ideal ou teoria da democracia, tratando-se, assim, de leitura fundamental naquele contexto de pós-guerra, em que ficava claro que a democracia não era uma inevitabilidade histórica. Para o cientista político David Easton (1949), de Chicago, identificado com a perspectiva comportamental da sua disciplina, um dos principais méritos de Michels foi trazer a Psicologia e a Sociologia para o estudo do fenômeno político. Segundo o resenhista, os usos políticos do trabalho de Michels terminaram produzindo efeitos negativos para a pesquisa científica sobre temas a ele relacionados, como poder e burocracia, colocando-os sob suspeição. Ao mesmo tempo, podiam levar à falsa conclusão de que a distribuição de poder democrática era definitivamente impossível. Já para o sociólogo Morris Janowitz (1949-1950), também da Universidade de Chicago, o trabalho de Michels, analisando as complexidades do comportamento político de modo compreensivo, era dotado de atualidade. Suas generalizações, além disso, eram formuladas com grande concretude e insight. Embora não formule explicitamente a sua opinião, Janowitz responde à acusação feita ao autor de que seria um pessimista, totalitário, citando um trecho de Sociologia em que se diz que o que se tratava não era de saber se a democracia ideal era realizável, mas sim se ela era possível e desejável em um contexto concreto. E na visão de Gabriel A. Almond (1950), cientista político de Yale, que fez seu doutorado em Chicago trabalhando com Lasswell, o livro era importante sobretudo para os que conduziam pesquisas sobre comportamento político. Na sua leitura, Michels, era um

31 Seria importante refletir sobre a reedição e a difusão de Michels nos Estados Unidos em um quadro de Guerra Fria. Não há, porém, condições de fazê-lo no momento, dadas as informações disponíveis e, também, os limites de espaço deste artigo. 
pensador realista, destruidor de ilusões liberais, partindo da premissa de que a verdade científica era oposta à utopia. $\mathrm{O}$ problema das conclusões de Michels, avaliava Almond, advinha do fato que se baseavam em um estudo interno dos partidos e não das relações entre eles.

A partir dos anos 1950, a leitura de Michels como um realista e de Sociologia dos partidos políticos como uma crítica não da democracia em geral, mas da utopia e do radicalismo democráticos foi ganhando espaço e, mesmo com contestações, se generalizando. Em um artigo de 1953 na American Political Science Review intitulado "The law of oligarchy", C. W. Cassinelli, do Whitman College, afirmava que a lei formulada por Michels era uma das mais interessantes generalizações do campo das Ciências Sociais. Dizia que os comentários sobre ela foram, em geral, motivados por um desejo de de atacá-la ou de apoiá-la, mas que ninguém havia ainda feito uma tentativa séria de entendê-la antes de julgála. E era isso que buscava fazer no texto, concluindo que a lei não era incompatível com a democracia. Se a oligarquia era inevitável, o seu controle não era, vindo justamente de fora, da concorrência entre organizações, impedindo que uma se sobrepusesse às demais.

Um elemento importante nessa generalização, já na década de 1960, foram as introduções agregadas a novas edições de Sociologia dos partidos políticos, como a do sociólogo Seymour Martin Lipset, de 1962, à época professor da Universidade de Berkeley. Sua análise é em parte influenciada pela de Burnham. Assim como este, Lipset, que também militou no trotskismo na juventude, teve em Michels uma base, de início, para criticar o stalinismo. À diferença de Burnham, que terminou por ser identificado como um pensador de direita, Lipset, depois de passar por diferentes grupos de orientação socialista, assumiu a posição política definida por ele mesmo como a de um democrata conservador (LIPSET, 2003). Quando escreveu a introdução, Lipset abandonara o Partido Socialista havia cerca de um ano. Para ele, Michels produziu um argumento contrário à concepção de democracia popular direta de Rousseau, fundamento de boa parte das teorias democrática e socialista tradicionais. Mostrou que os problemas da democracia eram característicos de qualquer sistema social complexo. A precisão de suas previsões em relação ao comportamento futuro dos partidos políticos e de outras organizações democráticas, combinada com o fato de que identificou os processos responsáveis por isso, tornaram Sociologia dos partidos políticos um clássico, um dos livros mais influentes do século XX. Lipset afirma que Michels foi criticado como um pessimista, enxergando apenas os limites da democracia como um fim e, assim, deixando de atentar para o quanto ela pode ser um meio para que grupos alcancem seus objetivos. Para ele, porém, o autor, que terminou aceitando que o melhor governo era aquele sob a chefia de um líder carismático, ainda lutava por mais democracia como forma de contrabalançar as tendências oligárquicas à época em que escreveu o livro. O possível pessimismo traduzido em Sociologia dos partidos políticos devia-se, seguia Lipset o diagnóstico formulado também por outros autores, à sua ênfase exclusiva na estrutura interna dos partidos. De todo modo, o livro influenciou a produção de uma visão mais realista da democracia, fundada não na negação das elites, mas na competição entre elas. Mesmo podendo ser internamente oligárquicas, as organizações, concorrendo entre si, contribuem para manter a democracia (LIPSET, 1966 [1962]).

Outra introdução que traduzia essa visão, agora na Itália, mas produzida por um autor que, embora de origem europeia, fez seu doutorado e sua carreira acadêmica nos Estados Unidos, foi a do cientista político Juan J. Linz na edição de Sociologia dos partidos políticos de $1966^{32}$. Linz (2006) sustenta que, em 1911, Michels ainda pregava a democracia e o socialismo, mas como ideais que apenas de forma imperfeita poderiam ser alcançados. Apontar obstáculos à democracia, como fez Michels, não era o mesmo que assumir uma postura antidemocrática. Era legítimo tentar provar a impossibilidade empírica da democracia e ao mesmo tempo desejá-la em uma perspectiva normativa. Afinal, uma teoria científica não podia

32 O texto da introdução foi editado em inglês, em 2006, mas não como apresentação a uma nova edição do livro e sim como uma coletânea de ensaios de Linz. Segundo o autor (LINZ, 2006, p. 1), que dedica o texto a Lipset, chamado de amigo e professor, a edição atual mantinha o argumento básico da versão original que, embora publicada em italiano, foi escrita em inglês. Foi à versão atual que foi possível ter acesso para este artigo. 
ser rotulada de pró ou antidemocrática. O que importava era se era verdadeira, adequada aos fatos e logicamente consistente. A introdução de Linz é obviamente mais complexa e densa do que o que dela aqui se reteve. Entretanto, os pontos destacados indicam o sentido mais geral do argumento, que conflui para as leituras de Michels que foram se conformando a partir de fins dos anos 1930, como um pensador realista e não um pessimista antidemocrático, e para Sociologia dos partidos políticos como uma contribuição objetiva, consistente e escorada na empiria, à identificação dos obstáculos que se contrapõem à afirmação da democracia e à formulação de uma noção de democracia efetiva, que não nega a inevitabilidade das minorias dirigentes, mas que impõe limites ao seu poder pelo livre exercício da concorrência ${ }^{33}$.

Introduções definem um roteiro e um quadro de leitura de uma obra, bem como de questões que suscitará. Intoduzindo a edição italiana de 1966 de Sociologia dos partidos políticos, Linz contribuiu para internacionalizar uma forma de recepção e de apropriação do livro e de Michels que tinha raízes nas Ciências Sociais americanas, a Política em particular, a partir de fins dos anos 1930. E, se pôde fazê-lo, foi porque era reconhecido na Itália como portador de uma competência e de uma autoridade no assunto, o que remete a uma questão enunciada no início deste artigo. Embora Michels vivesse na Itália na época em que Sociologia dos partidos políticos foi escrito, foi sua apropriação nos Estados Unidos que, imbricando-se com uma forma própria de conceber a democracia, generalizou-se e, ainda que contestada, impôs-se como dominante. De tal forma que foi um autor formado e radicado nos Estados Unidos quem redigiu a introdução italiana do livro. Na verdade, também como já se apontou, a projeção maior da leitura americana não foi uma exclusividade de Michels, observando-se igualmente, ainda que em diferentes graus, com os demais autores italianos cujas ideias foram tomadas como fundamento daquela concepção, Mosca e Pareto. Isso guarda relação

33 O verbete sobre Michels escrito por Linz (1968) para a International Encyclopedia of the Social Sciences segue a mesma estrutura da introdução italiana de 1966. Nele, porém, o autor assume um tom menos assertivo em relação ao realismo de Michels. também, é claro, com a posição dominante ocupada pela Ciência Política americana na hierarquia internacional da disciplina. Discutir essa questão de maneira sistemática, todavia, seria inviável nos limites deste artigo. Por ora é suficiente relembrar a observação de Norberto Bobbio referida no início, de que embora tenha nascido na Itália, foi nos Estados Unidos que o elitismo ganhou sua cidadania na Ciência Política contemporânea.

\section{CONSIDERAÇÕES FINAIS}

Pode-se extrair como conseqüência da afirmação de Bobbio que, tivesse o elitismo ficado restrito aos limites da Itália, seu destino seria diverso. Afinal, nas trocas acadêmicas internacionais os países têm pesos diferenciais na definição de hierarquias de objetos, metodologias e teorias legítimos, bem como de agentes individuais e institucionais reconhecidos como mais capazes e autorizados. Se a passagem e o reconhecimento pelos Estados Unidos conferiram projeção e relevância ao elitismo, isso vale inclusive para a Itália do pós-II Guerra, com um debate intelectual fortemente marcado pelo marxismo e buscando exorcizar o fantasma do fascismo. Ou seja, ganhando projeção fora da Itália, o elitismo se impôs como tema legítimo de debate acadêmico nesse próprio país. Mais, o reconhecimento fora da Itália, sobretudo pela Ciência Política norte-americana, equivaleu a conferir um selo de qualidade ao pensamento social italiano. E isso de tal modo que Michels, de origem alemã e tendo sua experiência na socialdemocracia alemã como principal base para a elaboração de Sociologia dos partidos políticos é reivindicado como um pensador italiano.

Discutir a matriz fundamental do pensamento de Michels, de todo modo, não é o mais relevante para os objetivos deste artigo. O que importa é que as questões acima indicam que não depende unicamente da qualidade de um texto, do poder das suas idéias o seu reconhecimento. Além disso, como se procurou demonstrar, o reconhecimento é, ao mesmo tempo, a atribuição de uma determinada representação ao texto e seu autor, a imposição de leituras e interpretações legítimas por processos que escapam muitas vezes ao controle deste, levados a efeito em contextos distintos do original. Isso se faz por um conjunto de agentes que envolve, além ou não do próprio autor, departamentos, universidades, professores, 
agências de fomento, editoras, tradutores, resenhistas, revistas, entre outros, posicionados de forma diferencial, com estratégias diversas, para os quais o investimento nos textos e nos autores pode ter sentidos e objetivos distintos. E na medida em que as estratégias são conformadas em configurações históricas determinadas, com horizontes de possibilidades e expectativas definidos, investimentos e leituras se alteram ao longo do tempo. Com isso, mesmo os chamados clássicos podem não permanecer inalterados, seja por iniciativa do próprio autor, como no caso de Michels, que promovia modificações a cada nova edição de Sociologia dos partidos políticos de modo a responder às críticas, ou não. Mesmo que o texto em si não seja modificado, as marcas que lhe vão sendo agregadas nas capas, contracapas, orelhas, prefácios, entre outros, pesam sobre sua recepção, sua leitura, sua interpretação.

$\mathrm{O}$ que se procurou demonstrar por meio da trajetória de Michels e de Sociologia dos partidos politicos, com ênfase na sua passagem pelos Estados Unidos, foi o quanto a análise histórica das condições sociais de circulação e de recepção de um texto permite ganhar em compreensão e desnaturalizar leituras impostas.

Mario Grynszpan (mario.grynszpan@fgv.br) é Mestre e Doutor em Antropologia Social pela Universidade Federal do Rio de Janeiro (UFRJ) e Professor da Fundação Getúlio Vargas (FGV) e do Departamento de História da Universidade Federal Fluminense (UFF).

\section{REFERÊNCIAS BIBLIOGRÁFICAS}

ALBERTONI, E. A. 1974. Gaetano Mosca e la teoria della classe politica. Firenze: Sansoni.

1985. Dottrina della classe politica e teoria delle elites. Milano: Giuffrè Editore.

1989a. Prefazione. In: ALBERTONI, E. A. \& CONTI, G. G. (orgs.). Elitismo e democrazia nella cultura politica del Nord-America (Stati Uniti-Canada-Messico). Milano: Giuffrè.

1989b. Alle origini della conoscenza critica dell'elitismo dei classici italiani negli USA: Arthur Livinston e James H. Meisel. In: ALBERTONI, E. A. \& CONTI, G. G. (orgs.). Elitismo e democrazia nella cultura politica del NordAmerica (Stati Uniti-Canada-Messico). Milano: Giuffrè.

ALMOND, G. A. 1950. "Political Parties: A Sociological Study of the Oligarchical Tendencies of Modern Democracies", by Robert Michels. American Sociological Review, Washington (DC), v. 15, n. 1, p. 146, Feb.

1988. Separate Tables: Schools and Sects in Political Science. PS: Political Science and Politics, Washington (DC), v. 21, n. 4, 828-842, Autumn. Disponível em: http://courses. essex.ac.uk/gv/gv994/Almond-Separate\% 20Tables.pdf. Acesso em: 15.out.2012.
BANNISTER, R. C. 1987. Sociology and Scientism. The American Quest for Objectivity, 18801940. Chapel Hill: University of North Carolina.

BEARD, C. A. 1917. "Political Parties: A Sociological Study of the Oligarchical Tendencies of Modern Democracy", by Robert Michels. Political Science Quarterly, New York, v. 32, n. 1, p. 153155, Mar.

BEETHAM, D. 1977a. From Socialism to Fascism: The Relation between Theory and Practice in the Work of Robert Michels. I. From Marxist Revolutionary to Political Sociologist. Political Studies, Hoboken, v. XXV, n. 1, p. 3-24, Mar.

1977b. From Socialism to Fascism: The Relation between Theory and Practice in the Work of Robert Michels. II. The Fascist Ideologue. Political Studies, Hoboken, v. XXV, n. 2, p. 161181, June.

BOBBIO, N. 1966. Nota per la presente edizione. In: MOSCA, G. La classe politica. Bari: Laterza.

1976. Élites, Teoria delle. In: BOBBIO, N.; MATTEUCCI, N. \& PASQUiNO, G. (orgs.). Dizionario di política. Torino: UTET.

BONGIORNO, A. 1930. A Study of Pareto's Treatise on General Sociology. American Journal of Sociology, Washington (DC), v. XXXVI, n. 3, p. 349-370, Nov. 
BONNELL, A. G. 2011. Oligarchy in Miniature? Robert Michels and the Marburg Branch of the German Social Democratic Party. German History, Oxford, v. 29, n. 1, p. 23-35.

BORGOGNE, G. 1999. L'itinerario político e intellettuale di James Burnham: dal trockismo all'ultraconservatorismo. Studi Storici, Roma, v. 40, n. 3, 755-797, jul.-sep.

BOURDIEU, P. 2002. Les Conditions sociales de la circulation internationale des idées. Actes de la Recherche en Sciences Sociales, Paris, n. 145, p. 3-8, déc. Disponível em: http:// www.persee.fr/web/revues/home/prescript/ article/arss_0335-5322_2002_num_145_1_ 2793. Acesso em: 15.out.2012.

BROOKS, R. C. 1911. Zur Soziologie des Parteiwesens in der Modernen Demokratie. Review. Political Science Quarterly, New York, v. 26, n. 1, p. 142-144, Mar.

BURNHAM, J. 1943. The Machiavellians. Defenders of Freedom. New York: J. Day.

BURNS, C. D. 1917. "Political Parties: A Sociological Study of the Oligarchical Tendencies of Modern Democracy", by Robert Michels. International Journal of Ethics, v. 27, n. 2, p. 259-260, Jan.

CALHOUN, C. 2004. Les Transformations institutionnelles des sciences sociales américaines. In: HEILBRON, J. ; LENOIR, R. \& SAPIRO, G. (orgs.). Pour une Histoire des Sciences sociales: hommage à Pierre Bourdieu. Paris: Fayard.

CAMAVITTO, D. 1936. Roberto Michels - In Memoriam. American Sociological Review, Washiongton (DC), v. 1, n. 5, p. 797-799, Oct.

CAREY, J. T. 1975. Sociology and Public Affairs: The Chicago School. Beverly Hills: Sage.

CASSINELLI, C. W. 1953. The Law of Oligarchy. American Political Science Review, Washington (DC), v. 47, n. 3, p. 773-784, Sept.

COOK, P. J. 1971. Robert Michels' Political Parties in Perspective. The Journal of Politics, Cambridge (UK), v. 33, n. 3, p. p. 773-796, Aug.

DAHL, R. A. 1961. The Behavioral Approach in Political Science: Epitaph for A Monument to A Successful Protest. American Political Science
Review, Washington (DC), v. 55, n. 4, p. 763772, Dec. Disponível em: http://www.uky.edu/ $\sim$ clthyn2/PS671/Dahl APSR1961.pdf. Acesso em: 15.out.2012.

DICKINSON, E. D. 1916. "Political Parties: A Sociological Study of the Oligarchical Tendencies of Modern Democracy", by Robert Michels. American Journal of Sociology, Washington (DC), v. 22, n. 1, p. 108-109, July.

EASTON, D. 1949. "Political Parties", by Robert Michels. American Journal of Sociology, Washington (DC), v. 55, n. 3, p. 310-311, Nov.

1964. The Political System. An Inquiry into the State of Political Science. New York: A. A. Knopf.

EINAUDI, M. M. 1935. Pareto as I Knew Him. Atlantic Monthly, v. CLVI, p. 336-346, Jul.-Dec. Disponível em: http://www.carloalberto.org/ assets/pareto/michels35.pdf. Acesso em: 15.out.2012.

ELIAS, N. 1994. Mozart-Sociologia de um gênio. Rio de Janeiro: Zahar.

FARR, J. \& SEIDELMAN, R. (eds.). 1993. Discipline and History. Political Science in the United States. Ann Arbor: University of Michigan.

FOSDICK, R. 1989. The Story of the Rockefeller Foundation. New Brunswick: Transaction.

GIANINAZZI, W. \& LAGARDELLE, H. 1999. La Démocratie difficile à l'ère des masses. Lettres d'Hubert Lagardelle à Robert Michels (1903-1936). Mil Neuf Cent, Paris, n. 17, p. 103-148. Disponível em: http://www.persee.fr/ web/revues/home/prescript/article/ mcm 1146-1225 1999 num 1711206. Acesso em: 15.out.2012.

GRAZIANO, L. 1991. The Development and Institutionalization of Political Science in Italy. In: EASTON, D.; GUNNELL, J. \& GRAZIANO, L. (eds.). The Development of Political Science. A Comparative Survey. London: Routledge.

GRUBER, C. S. 1975. Mars and Minerva. World War I and the Uses of the Higher Learning in America. Baton Rouge: Louisiana State University. 
GRYNSZPAN, M. 1996. A teoria das elites e sua genealogia consagrada. $B I B$, Rio de Janeiro, n. 41, 35-83, $1^{\circ}$ semestre. Disponível em: http:/ /www.anpocs.org/portal/index.php?option=c om_docman\&task=doc_download\&gid= $462 \&$ Itemid=282. Acesso em: 15.out.2012.

1999. La Théorie des élites aux États-Unis: conditions socials de réception et d'appropriation. Genèses, Paris, v. 37, n. 1, p. 27-43. Disponível em: http://www.persee.fr/ web/revues/home/prescript/article/ genes_1155-3219_1999_num_37_1_1593. Acesso em: 15.out.2012.

JANOWITZ, M. 1949-1950. Michels, Robert. "Political Parties: A Sociological Study of the Oligarchical Tendencies of Modern Democracy". Public Opinion Quarterly, Oxford, v. 13, n. 4, p. 705-706, Winter.

KARL, B. D. 1974. Charles E. Merriam and the Study of Politics. Chicago: University of Chicago.

1979. Executive Reorganization and Reform in the New Deal. The Genesis of Administrative Management, 1900-1939. Chicago: University of Chicago.

1985. The Uneasy State. The United States from 1915 to 1945 . Chicago: University of Chicago.

KING, C. L. 1916. "Political Parties: A Sociological Study of the Oligarchical Tendencies of Modern Democracy", by Robert Michels. Annals of the American Academy of Political and Social Science, Philadelphia, v. 66, p. 269-270, July.

LE BON, G. 1922. Psychologia das multidões. Rio de Janeiro: Garnier.

LEDERLE, J. W. 1949. "Political Parties" by Robert Michels. Annals of the American Academy of Political and Social Science, Philadelphia, v. 266, p. 225-226, Nov.

LINZ, J. J. 1968. Michels, Robert. In: SILLS, D. L. (ed.). International Encyclopedia of the Social Sciences. v. 10. New York: Macmillan.

2006. Robert Michels, Political Sociology, and the Future of Democracy. New Brunswick: Transaction.

LIPPMAN, W. 1922. Public Opinion. New York: Harcourt.
1925. The Phantom Public. New York: Harcourt.

1955. Essays in the Public Philosophy. Boston: Little, Brown.

LIPSET, S. M. 1966 (1962). Introduction. In: MICHELS, R. Political Parties: A Sociological Study of the Oligarchical Tendencies of Modern Democracy. New York: Free.

2003. Steady Work: An Academic Memoir. The American Sociologist, New York, v. 34, n. 1-2, p. 112-131, Spring-Summer.

LIVINGSTON, A. s/d. Introduction. In: MOSCA, G. The Ruling Class (Elementi di scienza politica). New York: McGraw-Hill.

MALANDRINO, C. 2005. Michels e la scuola di economia di Torino. Torino: Università degli Studi di Torino.

MARPEAU, B. 1991. Les stratégies de Gustave Le Bon. Mil Neuf Cent, Paris, n. 9, p. 115128. Disponível em: http://www.persee.fr/ web/revues/home/prescript/article/ mcm_1146-1225_1991_num_9_1_1042. Acesso em: 15.out.2012.

2010. La «Bibliothèque de Philosophie Scientifique » de Flammarion. Revue d'Histoire Moderne et Contemporaine, Paris, v. 4, n. 57, p. 185-210, oct.-déc.

MAY, J. D. 1965. Democracy, Organization, Michels. American Political Science Review, Washington (DC), v. 59, n. 2, p. 417-429, June. Disponível em: http:// people.brandeis.edu/ woll/michels.pdf. Acesso em: 15.out.2012.

MERRIAM, C. E. 1919. American Publicity in Italy. American Political Science Review, Washington (DC), v. 13, n. 4, p. 541-555, Nov.

MICHELS, G. L. 1937. Opere di Roberto Michels. Annali della Facoltà di Giurisprudenza, v. XLIX, p. 37-76.

MICHELS, R. 1911. Zur Soziologie des Parteiwesens in der Modernen Demokratie. Unter Suchungen über die Oligarchischen Tendenzen des Gruppenleben. Leipzig: W. Klinkhardt.

1914. Les Partis politiques. Essai sur les tendances oligarchiques des démocraties. Paris: Flammarion. 
1915. Political Parties. A Sociological Study of the Oligarchical Tendencies of Modern Democracy. New York: Hearst's International.

1924 (1912). La sociologia del partito politico nella democrazia moderna. Studi sulle tendenze oligarchiche degli agregati politici. Torino: Torinese.

1982. Sociologia dos partidos políticos. Brasília: UNB.

2001 (1925). Para uma sociologia dos partidos políticos na democracia moderna: investigação sobre as tendências oligárquicas na vida dos agrupamentos políticos. Lisboa: Antígona.

MOSCA, G. s/d. The Ruling Class (Elementi di scienza politica). New York: McGraw-Hill.

. 1923. Elementi di scienza politica.Torino: F. Bocca.

MOSCOVICI, S. 1985. L'Âge des foules: un traité historique de psychologie des masses. Bruxelles: Complexe.

MÜLLER, R. 2002. Biografie Roberto Michels. In: . (ed.). 50 Klassiker der Soziologie. Disponível em: http://agso.uni-graz.at/lexikon/ klassiker/michels/34bio.htm. Acesso em: 15.jul.2012.

OREN, I. 2000. Uncritical Portrayals of Fascist Italy and of Iberic-Latin Dictatorships in American Political Science. Comparative Studies in Society and History, Cambridge (UK), v. 42, n. 1, p. 87118, Jan.

PARETO, V. 1965 (1902). Les systèmes socialistes. In:__. Euvres complètes de Vilfredo Pareto, v. 5. Genève: Droz.

POUTHIER, J.-L. 1986. Roberto Michels et les syndicalistes révolutionnaires français. Cahiers Georges Sorel, Paris, n. 4, 39-60. Disponível em: http://www.persee.fr/web/revues/home/ prescript/article/mcm_07558287_1986_num_4_1_921. Acesso em: 15.out.2012.

RICCI, D. M. 1984. The Tragedy of Political
Science. Politics, Scholarship, and Democracy. New Haven: Yale University.

RINGER, F. K. 2000. O declínio dos mandarins alemães: a comunidade acadêmica alemã, 18901933. São Paulo: USP.

ROSS, D. 1997. The Origins of American Social Science. Cambridge (UK): Cambridge University.

SCAFF, L. A. 1981. Max Weber and Robert Michels. American Journal of Sociology, Washignton (DC), v. 86, n. 6, p. 1269-1286, May.

SEIDELMAN, R. \& HARPHAM, E. J. 1985. Disenchanted Realists. Political Science and the American Crisis, 1884-1984. Albany: State University of New York.

SIGAUD, L. 2002. The Vicissitudes of The Gift. Social Antyhropology, Cambridge (UK), v. 10, n. 3, p. 335-358, Oct.

SMALL, A. W. 1911. Review. American Journal of Sociology, Chicago, v. 17, n. 3, 408-409, Nov.

SOLA, G. 1996. Storia della scienza politica. Teorie, ricerche e paradigmi contemporanei. Roma: La Nuova Italia Scientifica.

SOMIT, A. \& TANEHAUS, J. 1967. The Development of American Political Science: from Burgess to Behavioralism. Boston: Allyn and Bacon.

TUCCARI, F. 1993. I dilemma della democrazia moderna: Max Weber e Robert Michels. Roma: Laterza.

WALDO, D. 1975. Political Science: Tradition, Discipline, Profession, Science, Enterprise. In: GREENSTEIN, F. I. \& POLSBY, N. (eds.). Handbook of Political Science. V. 1. Reading: Addison-Wesley.

WORCESTER, K. \& SIBLEY, E. 2001. Social Science Research Council, 1923-1998. New York: Social Science Research Council.

WORTHINGTON, R. V. 1933. Pareto, the Karl Marx of Fascism. The Economic Forum, p. 311-315, Summer. 


\section{Outras Fontes}

Obituary: Roberto Michels - 1876-1936. 1936. American Journal of Sociology, Chicago, v. 42, n. 2, p. 247-248, Sept.

Roberto Michels, Economist, Dead. 1936. The New York Times, May $7^{\text {th }}$.

WORLDCAT. s/d. Edições de "Political parties; a sociological study of the oligarchical tendencies of modern democracy”. Disponível em: http://www.worldcat.org/title/politicalparties-a-sociological-study-of-theoligarchical-tendencies-of-moderndemocracy/oclc/7070564/editions?start_editi on $=151 \&$ sd $=$ desc $\&$ referer $=$ di\&se $=$ yr\&editions View $=$ true \& $\mathrm{f} \% 20 . \% 20$ Por $\% 20 . \% 20 \mathrm{q}=$. Acesso em: 12.jul.2012. 
TOWARD A HISTORICAL SOCIOLOGY ON THE CIRCULATION AND RECEPTION OF TEXTS: ROBERT MICHELS AND HIS SOCIOLOGY OF POLITICAL PARTIES IN THE UNITED STATES

\section{Mario Grynszpan}

Taking Pierre Bourdieu's considerations on the importance of studying the social conditions of the international circulation of ideas as my point of departure, my purpose here is to advance a historical sociology of the circulation and reception of Robert Michels' Sociology of political parties. I focus on Michels and his book's trajectory in the United States, attempting to show how a way of reading the text and representing its author took hold which still prevails today becoming the basis for its celebration and consecration as a classic of Political Science. With these purposes in mind, I engage in a systematic comparison of different editions and translations of the book, as well as reviews that were written of it. I attempt to identify different types of interpretations that were made over time, associating them with elements of the author's biographical trajectory and the history of the social sciences in that country - and political science in particular: from early perceptions as an author who was pessimistic about democracy or even anti-democratic and associated with fascism to his postwar interpretation as a realist thinker whose theses became the basis for a notion of democracy associated with liberal pluralism.

KEYWORDS: Robert Michels; Political Parties; Circulation of Ideas; Reception of Ideas; Political Science; Pluralism. 

DE TEXTES : ROBERT MICHELS ET LA SOCIOLOGIE DES PARTIS POLITIQUES AUX ÉTATS-UNIS

\section{Mario Grynszpan}

L'objectif de cet article est, en partant des considérations de Pierre Bourdieu autour de l'importance de l'étude des conditions sociales de la circulation internationale d'idées, de faire une sociologie historique de la circulation et de la réception du livre La Sociologie des partis politiques, de Robert Michels. Dans l'article, l'accent est mis sur le passage de Michels et son livre par les États-Unis, cherchant à montrer comment, à partir de là, s'est consolidée une forme de lecture du texte et une représentation de l'auteur qui est aujourd'hui prédominante et à la base de sa célébration et de sa consécration comme un classique de la Science Politique. Pour cela, on fait une comparaison systématique de différentes éditions et traductions du livre, bien comme d'analyses produites à partir de lui, cherchant à identifier des lectures distinguées faites au fil du temps, en leur associant à des éléments de la trajectoire biographique de 1'auteur, bien comme à l'histoire des Sciences Sociales aux États-Unis et, en particulier, à l'histoire de la Science Politique dans ce pays . D'un auteur pessimiste par rapport à la démocratie, ou même avec une tendance antidémocratique, associé au fascisme, Michels a été vu dans le post-Guerre comme un philosophe réaliste, et ses thèses autant qu'une base pour la formulation d'une notion de démocratie identifiée avec le pluralisme libéral.

MOTS-CLÉS: Robert Michels; partis politiques; circulation d'idées; réception d'idées; Science Politique; pluralisme. 